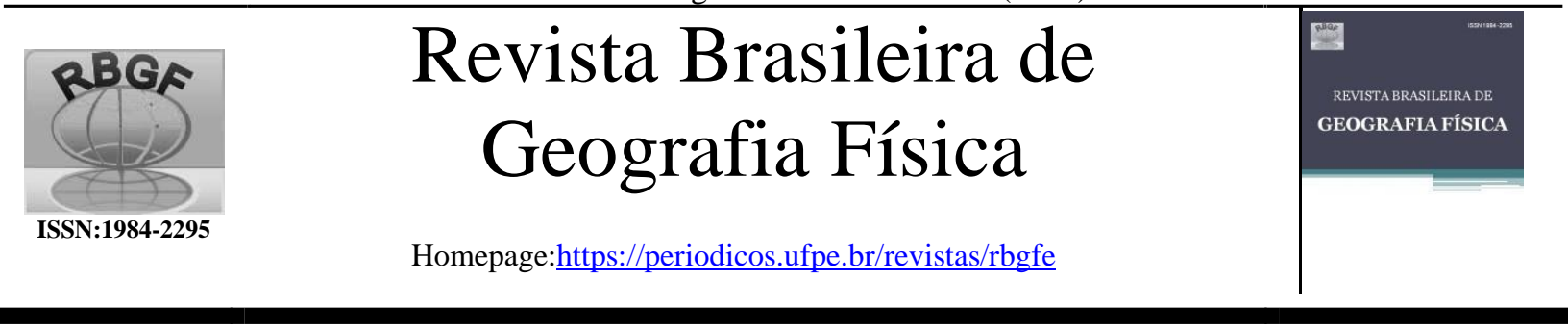

\title{
Análise das mudanças morfológicas em escala de detalhe em voçoroca urbana utilizando perfilamento a laser e veículo aéreo não tripulado
}

\author{
Fernando da Silva Alexandre ${ }^{1}$, Ana Lúcia Bezerra Candeias², Daniel Dantas Moreira Gomes³
}

${ }^{1}$ Programa de Pós-Graduação em Desenvolvimento e Meio Ambiente, Universidade Federal de Pernambuco. Av. Prof. Moraes Rego, 1.235, CEP 50670-901, Recife, PE, Brasil - fnando257@ gmail.com (autor correspondente). ${ }^{2}$ Departamento de Engenharia Cartográfica, Universidade Federal de Pernambuco. Av. Prof. Moraes Rego, 1.235, CEP 50670-901, Recife, PE, Brasil - analucia@ufpe.br. ${ }^{3}$ Programa de Pós-Graduação em Saúde e Desenvolvimento Socioambiental, Universidade de Pernambuco. R. Cap. Pedro Rodrigues, 105. CEP 55294-902, Garanhuns, PE, Brasil daniel.gomes@upe.br.

Artigo recebido em 17/06/2020 e aceito em 19/04/2021

\section{R E S UM O}

O solo é um dos recursos naturais mais importantes para a humanidade e vital para o funcionamento dos ecossistemas, a erosão linear do solo por processos hídricos é considerada um dos maiores modificadores naturais da paisagem. Dentre os processos erosivos lineares tem-se as voçorocas, que são uma forma típica de erosão nas regiões semiáridas, com alta atividade morfológica e dinâmica observável. A voçoroca urbana deste estudo se localiza no bairro Dom Hélder Câmara, na cidade de Garanhuns, agreste pernambucano, a voçoroca se localiza próxima a moradias, com casa a cerca de 13 metros de distância de sua borda, além de apresentar quase que completa ausência da cobertura vegetal arbórea e presença de culturas agrícolas em seu interior. $\mathrm{O}$ estudo em questão visou analisar as mudanças morfológicas da voçoroca na escala de 1:1.000 entre os anos de 2016 e 2018, através da quantificação e espacialização do material erodido, para tanto se utilizou dados de perfilamento a laser advindos do projeto PE3D e de modelo digital de terreno gerador a partir de um veículo aéreo não tripulado. Obteve-se como resultado que entre os dois anos houve aumento areal da voçoroca de cerca de $2.408,37 \mathrm{~m}^{2}$ de área total e foram erodidos cerca de 143,039,24 $\mathrm{m}^{3}$ de material em toda a área de estudo.

Palavras-chave: semiárido, erosão linear, voçorocas semiáridas.

\section{Analysis of the morphological changes in detail scale in urban gully using laser profiling and unmanned aerial vehicle}

\begin{abstract}
A B S T R A C T
The soil is one of the most important natural resources for de humankind and vital for de functional of the ecosystems, the linear erosion of the soil for process hydric is considered an of the big modificators of the natural landscapes. In the linear erosion have the gullies, then that are a typical in the region semiarid, with high morphological active and dynamic observable. The urban gully in this study is located in Garanhuns, Pernambuco, moreover, almost no preset tree vegetation, but present agricultural crops inside the gully. The present study has the objective to analyzed the morphological changes in the urban gully in the scale of 1:1.000 between 2016 and 2018, by the quantification and spatialization of the eroded material, this has utilized a laser profiling of the project PE3D and a terrain digital model created by unmanned aerial vehicle. Is obtained like result between the two years have an increase in the areas of the gully of $2.408,37 \mathrm{~m}^{2}$ and has eroded approximately $143.039,25 \mathrm{~m}^{3}$ of material in the total study area.
\end{abstract}

Keywords: semiarid, linear erosion, semiarid gullies.

\section{Introdução}

O solo é um dos recursos naturais mais importantes para a humanidade e vital para o funcionamento dos ecossistemas, a erosão linear do solo por processos hídricos é considerada um dos maiores modificadores naturais da paisagem (Daba; Rieger; Strauss, 2003; Vanmaercke et al., 2016; Liu et al., 2020; Martins et al., 2020). 
A erosão linear em áreas de agricultura elou expansão urbana é considerado um grave problema, principalmente em áreas semiáridas, onde há uma maior intensidade de chuvas em um curto período de tempo e cobertura vegetal de menor porte, o que a intensifica ( Poesen et al., 2003; Arabameri; Pourghasemi, 2019).

Os processos erosivos lineares são fatores naturais que podem ser potencializados ou mitigados através das ações antrópicas, sendo na maioria dos casos uma correlação entre esses fatores. Pode-se elencar como fator antrópico o desmatamento para pastagens ou áreas agrícolas e a urbanização sem planejamento, como fatores naturais se tem a pluviosidade, litologia, cobertura vegetal e a morfologia do relevo, dentre outros (Infanti Jr; Fornasari Filho, 1998; Sousa, 2010; Rubira; Melo; Oliveira, 2016; Liu et al., 2019; Souza et al., 2019; Arabameri et al., 2019; Arabameri; Pradhan; Bui, 2020; Real et al., 2020).

Dentre os processos erosivos lineares temse as voçorocas, que são definidas pela Soil Science Society of America (SSSA) como sendo a resultante da erosão causada por fluxos concentrados d'água, com largura e profundidade superior a $50 \mathrm{~cm}$ (Marchioro; Andrade; Oliveira, 2016). Segundo Marzolff e Poesen (2009) as voçorocas são uma forma típica de erosão nas regiões semiáridas, com alta atividade morfológica e dinâmica observável. Podem ser consideradas como sendo o estágio mais avançado de uma erosão linear, transportando tanto o solo superficial com o subsuperficial, seguindo-se pelo deslizamento e colapso das bordas e transporte do sedimento (Campo-Bescõs et al., 2013; Castillo; Gómez, 2016).

Na literatura há dois tipos de voçorocas, as permanentes e as efêmeras. Segundo CampoBescós et al. (2013) as permanentes podem ser definidas como sendo aquelas associadas a agricultura ou forte degradação da cobertura vegetal e causada por fluxo intermitente e concentrado de fluxo d'água, durante fortes chuvas, com sulcos profundos, variando entre 0,5 à 30 metros ou mais, entre a altura da borda e o sulco mais profundo. Enquanto que às efêmeras podem ser definidas como sendo aquelas em pequenos canais, em áreas com/sem presença de agricultura e com fluxo concentrado, porém sem apresentar evolução.

Com isso Li, Xiong e Tang (2019) trazem que a voçoroca é uma unidade geomórfica ativa na evolução das paisagens. Vários autores como Arabameri e Pourghasemi, (2019), Arabameri, Pradhan e Lombardo (2019); Domazetović et al.
(2019) e Gafurove e Yermolayev (2020) discutem que o processo de voçorocamento é natural e condicionado as características físicas, mas pode ser intensificado através de fatores antrópicos. Já que interferências em localidades através da remoção da vegetação, canalização do escoamento superficial podem alterar a inter-relação entre os fatores físicos de uma localidade

Quando se tratada de analises geomorfológicas de cunho temporal, um sistema de informação geográfica (SIG) traz grandes vantagens, já que permite análises quantitativas em escala de detalhe, correlacionando dados de diferentes instrumentos e permitindo mensurações e o monitoramento ambiental de forma repetitiva e com grande qualidade cartográfica ( Vrieling et al., 2007; Frankl et al., 2012; Liu et al., 2020).

Sabendo-se que o processo de voçorocamento é lento e irreversível, torna-se de grande importância compreender sua evolução, conhecendo em que estágio se encontra e quanto foi modificado, neste sentido pode-se realizar análises em ambiente SIG através da interpretação visual, perfis e cálculos de volume (Marzolff; Poesen, 2009; Real et al., 2020).

Assim este trabalho tem como objetivo analisar as mudanças morfológicas e quantificar os sedimentos erodidos na escala de 1:1.000 na voçoroca urbana Dom Helder Câmara, no município de Garanhuns.

\section{Material e métodos}

Área de estudo

A voçoroca urbana deste estudo se localiza no bairro Dom Hélder Câmara (DHC), na cidade de Garanhuns, agreste pernambucano, entre as seguintes coordenadas 9019923.7 e $9019440.7 \mathrm{Sul}$ e 775213.9 e 774714.3 Oeste (figura 1). O polígono que engloba a voçoroca tem área de $148.723,84 \mathrm{~m}^{2}$ e com variação altimétrica entre 813,539 e 895,419 m sobre o nível do mar. O entorno da voçoroca é povoado, com as casas mais próximas a cerca de 13 metros da voçoroca, há também presença de lixo na voçoroca, que apresenta cobertura vegetal reduzia e cultivos agrícolas.

Alexandre, Candeias e Gomes (2020) trazem que as chuvas na área se concentram entre os meses de maio a julho, com média de 782,5 mm anuais e temperatura média de $20,2^{\circ} \mathrm{C}$. Toda a área da voçoroca apresenta regossolos, compostos de areias quartzosas, com ou sem fragmentos rochosos, com textura variando de arenosa média à argilosa (Azambuja, 2007). 
Revista Brasileira de Geografia Física v.14 n.02 (2021) 758-769

Seleção da área de estudo

Para a seleção de uma área teste decidiu-se por uma que pudesse representar a forte dinâmica erosiva da em tal divisão, leva-se unicamente em consideração a área. Os autores dividem em grandes voçorocas $\left(>3.000 \mathrm{~m}^{2}\right)$, médias $(>1.000$

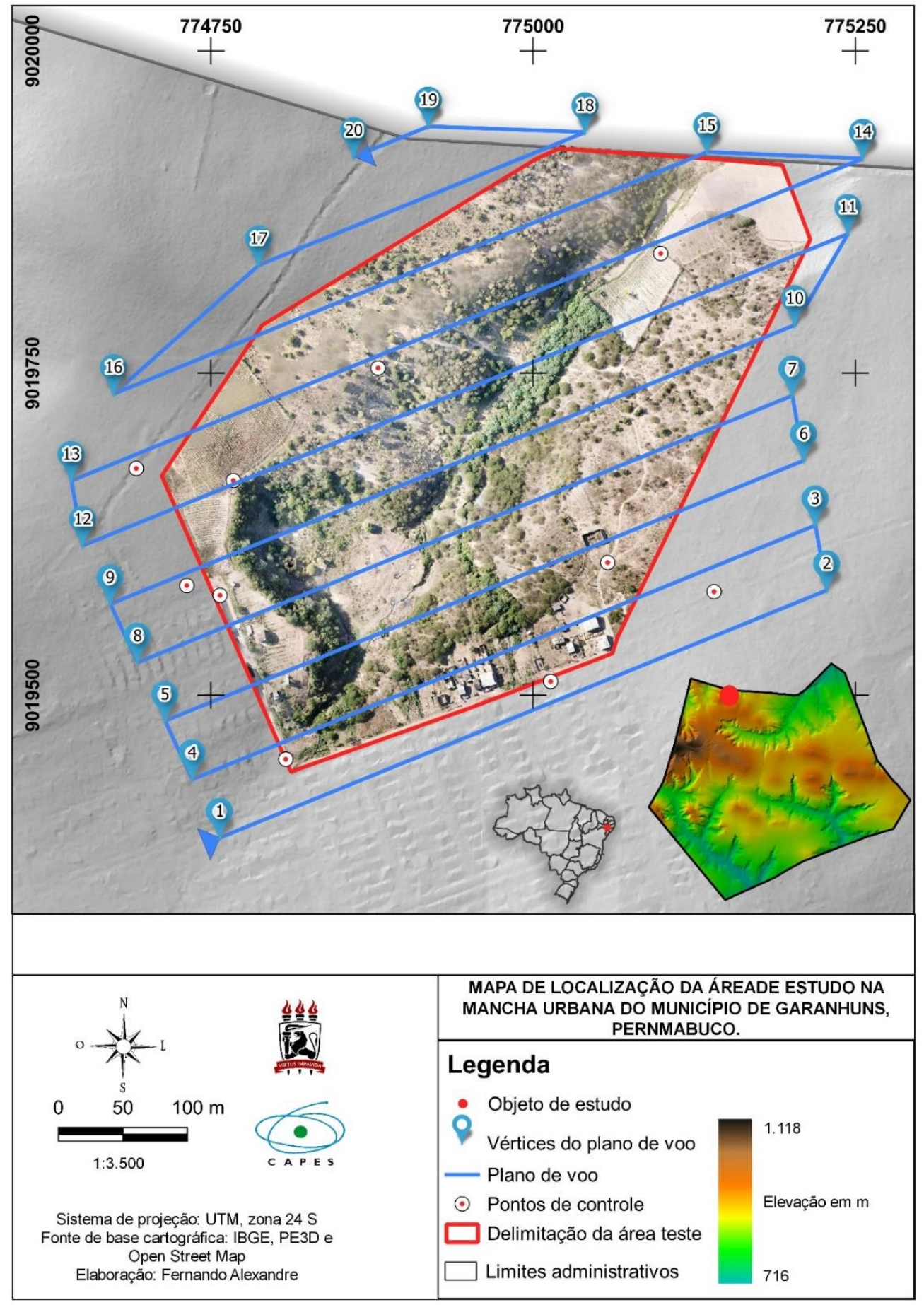

Figura 1. Localização geográfica do objeto de estudo.

localidade, para a escolha, levou-se em consideração o tamanho da voçoroca e a sua evolução temporal.

Liu e Liu (2020) trazem, baseados em pesquisas realizadas na China, que as voçorocas podem ser divididas e classificadas pela sua área, $\left.\mathrm{m}^{2}<3.000 \mathrm{~m}^{2}\right)$ e pequenas $\left(<1.000 \mathrm{~m}^{2}\right)$.

Enquanto para o critério de evolução temporal, se seguiu os escritos de Poesen et al. (2003), que dividem a evolução temporal em três categorias: curto ( $<3$ anos), médio (5 -50 anos) e 
longo prazo (> 50 anos) de acordo com o início do surgimento da feição.

Para a seleção da área, com base na correlação entre os dois critérios, decidiu-se por uma voçoroca de grandes dimensões $\left(>3.000 \mathrm{~m}^{2}\right)$ e média evolução temporal ( 5 - 50 anos). Assim podemos ter uma área amostral que não esteja estabilizada e devido ao seu tempo de surgimento, ainda apresente taxas erosivas (LIU; LIU, 2020). $\mathrm{Na}$ voçoroca do Bairro Dom Hélder Câmara onde pôde-se identificar as primeiras incisões no ano de 2000, a partir de imagens do Google Earth e em OUTUBRO DE 2020 possuía uma área de aproximadamente $80.643 \mathrm{~m}^{2}$.

\section{Material}

Para o desenvolvimento da pesquisa foram utilizados dados de órgão governamentais e dados adquiridos com equipamento próprio, abaixo os órgãos que disponibilizam os dados:

- Agência Pernambucana de águas e clima - APAC;

- Instituto Brasileiro de Geografia e Estatística - IBGE;

- Secretaria de desenvolvimento econômico do estado de Pernambuco.

\section{Levantamento $e$ processamento aerofotogramétrico}

Para a realização do levantamento aerofotogramétrico se seguiu os escritos de Silva et al. (2015) e Alexandre et al. (2017) que dividem entre as etapas de planejamento de voo, execução do voo e pós voo.

A etapa de planejamento de voo é aquela onde se analisa previamente a área a ser sobrevoada, levando-se em consideração a topografia, condições meteorológicas de velocidade do vento e possibilidade de chuva, para então se esquematizar a rota de voo. Se definiu a altitude de 100 metros de altura e sobreposição lateral de $70 \%$ e frontal de $80 \%$. Foram feitos 2 planos de voo, um com rota Norte-Sul e outro Leste-Oeste, visando o maior detalhamento e qualidade dos dados pós processados. Para uma maior qualidade cartográfica foram obtidos pontos de controle em solo, espalhados pela área a ser sobrevoada, se coletou 14 coordenadas.

A execução de voo se inicia com a análise do equipamento em solo, visando evitar problemas com a aeronave durante o voo. Para a realização
Pós consulta aos órgãos públicos, foram obtidos dados vetoriais e matriciais para conhecimento e análise da área, os dados utilizados foram os seguintes:

- Dados pluviométricos da estação Garanhuns/19 entre os anos de 1994 e 2018;

- Dados vetoriais dos limites administrativos na escala de 1:100.000 disponibilizados pelo IBGE;

- Modelo Digital de Terreno, Modelo Digital de Superfície e Ortoimagens da mancha urbana da cidade de Garanhuns, todos em escala de 1:1.000, sendo as ortoimagens com pixel de $12 \mathrm{~cm}$ e os modelos com pixel de 50 $\mathrm{cm}$, disponibilizados através do Pernambuco Tridimensional (PE3D), datados de abril de 2016.

Para a geração de dados mais recentes se utilizou de um veículo aéreo não tripulado da fabricante DJI, o Phantom 4, almejando a geração de produtos cartográficos para comparação com os dados do PE3D.

dos dois planos de voo, se levou cerca de 30 minutos e foram realizados em agosto de 2018.

Posteriormente a realização do voo, foi feito uma análise prévia das fotos através dos níveis de contraste, abertura da lente e ISO, verificando a qualidade das fotos, iniciou-se a etapa de processamento dos dados em escritório.

Para a geração dos produtos cartográficos utilizados se utilizou o Argisoft Metashape, com base nos escritos de Alexandre et al. (2017) divide nas seguintes etapas para a obtenção do produto final (ortomosaico e modelo digital de terreno), a saber: (I) calibração automática da câmera - com base nos dados do EXIF das fotografias; (II) alinhamento das fotos - a partir dos pontos em comum entre as fotografias para posterior correção através dos pontos de controle; (III) geração da nuvem de pontos densa - com base nas posições estimadas das fotografias são identificadas as coordenadas x, y e z; (IV) criação de um modelo digital de superfície de malha triangular - usando a nuvem de pontos como nós, é gerada uma estrutura do tipo vetorial com topologia do tipo nó-arco que representa a superfície através de um conjunto de faces triangulares interligadas; (V) criação do um modelo digital de superfície através da superfície 
gerada com a classificação da nuvem de pontos densa; e (VI) geração do ortomosaico - gerado a partir da texturização da geometria construída pela malha triangular.

\section{Padronização cartográfica}

Levando-se em consideração que os dados matriciais utilizados são distintos em resolução espacial e radiométrica, assim como a sua fonte de obtenção, há a necessidade de se padronizar os dados antes da realização da análise comparativa ( Rosa, 2009; Gomes, 2015; Alexandre; Candeias; Gomes, 2020) Então, todos os dados foram reprojetados para o Datum SIRGAS 2000, sistema de projeção UTM, zona $24 \mathrm{~S}$. Enquanto que para escala de análise, se definiu como sendo 1:1000 a escala padrão para se trabalhar os dados.

\section{Mudanças na superfície e quantificação de volume}

Com a obtenção de dados de dois estágios da evolução da voçoroca, é possível saber quais as áreas onde houve erosão ou deposição, a partir da realização em ambiente SIG de uma simples subtração entre os dois MDT, onde os valores dos pixels dos MDT são subtraídos, sendo o dado mais antigo o minuendo e o mais recente o subtraendo, com isso é possível gerar um novo dado com as áreas de perda e ganho de sedimento, conforme a Equação 1 (Marzolff; Poesen, 2009).

$$
\text { Erosão }=M D T_{V A N T}-M D T_{P e 3 D}
$$

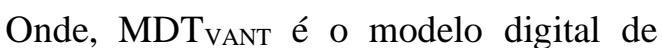
terreno gerado a partir do aerolevantamento e $\mathrm{MDT}_{\mathrm{Pe} 3 \mathrm{D}}$ é o modelo digital de terreno gerado pelo perfilamento à laser disponibilizado pelo Pernambuco Tridimensional.

Tendo ciência das áreas que sofreram erosão, torna-se importante quantificar o volume erodido e verificar as mudanças volumétricas. Para se realizar a comparação entre a duas superfícies, pode-se utilizar dados de hipsometria e de declividade dos diferentes períodos para se delimitar a área de influência da voçoroca e posterior quantificação do volume.

Poesen et al. (2003) argumentam que além da quantificação das mudanças volumétricas da voçoroca, necessita-se também a criação de perfis topográficos. A utilização de diversos perfis em uma mesma área ainda permite a visualização das micro-feições na morfologia, se tornando uma importante ferramenta para a compreensão dos processos de formação das voçorocas (LI; XIONG; TANG, 2019).
Li, Xiong e Tang (2019) ainda argumentam que a utilização de um único perfil pode facilmente verificar a verificação das características verticais, porém não é suficiente para a visualização da complexidade da forma. Portanto, torna-se indispensável o uso de $n$ perfis, assim pode-se verificar os níveis de bases locais (knickpoints).

Foram traçados seis perfis de forma que pudessem apresentar as diferenças morfológicas ao longo da voçoroca, de tal forma que seja perceptível as áreas onde houve erosão entre os dois anos, além de que os perfis foram delimitados com o intuito de se transpassarem, assim é possível ver o mesmo ponto a partir de distintas direções (MARZOLFF; POESEN, 2009). As direções dos perfis podem ser vistas na Figura 2.

\section{Resultados e discussão}

Com o processamento dos dados do VANT juntamente com os pontos de controle, foi possível se obter um ortomosaico com resolução espacial de $3,8 \mathrm{~cm}$ e um modelo digital de terreno com resolução espacial de $7,6 \mathrm{~cm}$, o erro posicional foi cerca de 3,71 cm em X, 4,42 em Y e 7,89 em Z, atendendo assim ao Padrão de Exatidão Cartográfica - PEC (Sopchaki et al., 2018).

\section{Métricas}

Verificada a qualidade dos produtos que seriam trabalhados, foi possível gerar informações topográficas do terreno, mais especificadamente a declividade dos dois anos, conforme a figura 3. Juntamente com as ortoimagens e o ortomosaico foi delimitar a área da voçoroca especificamente, sem levar em consideração a área do entorno, foi obtido uma área de cerca de $71.200,105 \mathrm{~m}^{2}$ no ano de 2016 e $73.608,475 \mathrm{~m}^{2}$ em 2018, em 2 anos e 3 meses houve um aumento de cerca de $2.408,37 \mathrm{~m}^{2}$ de área total.

A presença de vegetação arbórea altera de forma significativa o MDT gerado com as imagens do VANT, mesmo com a realização de filtragens não é possível remover completamente a rugosidade, o que dificultou a delimitação da área da voçoroca. Então, com base nos trabalhos de Hosseinalizadeh et al. (2019) e Cândido et al. (2020), decidiu-se não usar a área da voçoroca para as analises, mas todo o polígono da área, já que há uma conectividade erosiva com a voçoroca, como também influenciaria nos perfis e analises, caso não se trabalhasse com a mesma área, tendo em vista que há alteração na área da feição entre os dois anos, o polígono da área teste tem uma área de 
Revista Brasileira de Geografia Física v.14 n.02 (2021) 758-769

$148.723,84 \mathrm{~m}^{2}$ e é o delimitador em todas as análises, englobando tanto o MDTPe3D, como o MDTVAN T.

Com a classificação da declividade, se percebeu uma forte variação entre os dois anos nas áreas com alta declividade $\left(45-75^{\circ} \mathrm{e} \geq 75^{\circ}\right)$, chegando a uma diferença de $29.316,2 \mathrm{~m}^{2}$. Um dos fatores que influenciou diretamente foi a presença da vegetação remanescente, no caso do MDTVAN $\mathrm{T}$, já que a presença da rugosidade da vegetação se mostra presente, principalmente nas áreas onde há média declividade $\left(8-20^{\circ}\right)$ em 2016, aumentando posteriormente o gradiente de declividade em decorrência dos processos erosivos atuantes.

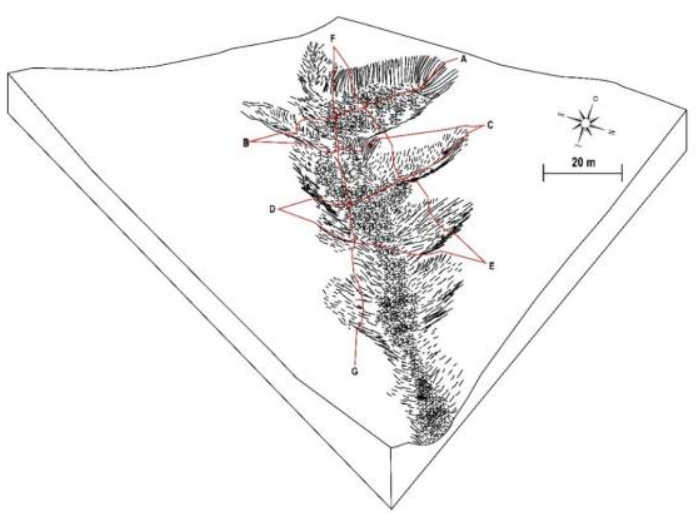

Figura 2. Desenho geomorfológico da área e perfis transversais traçados.

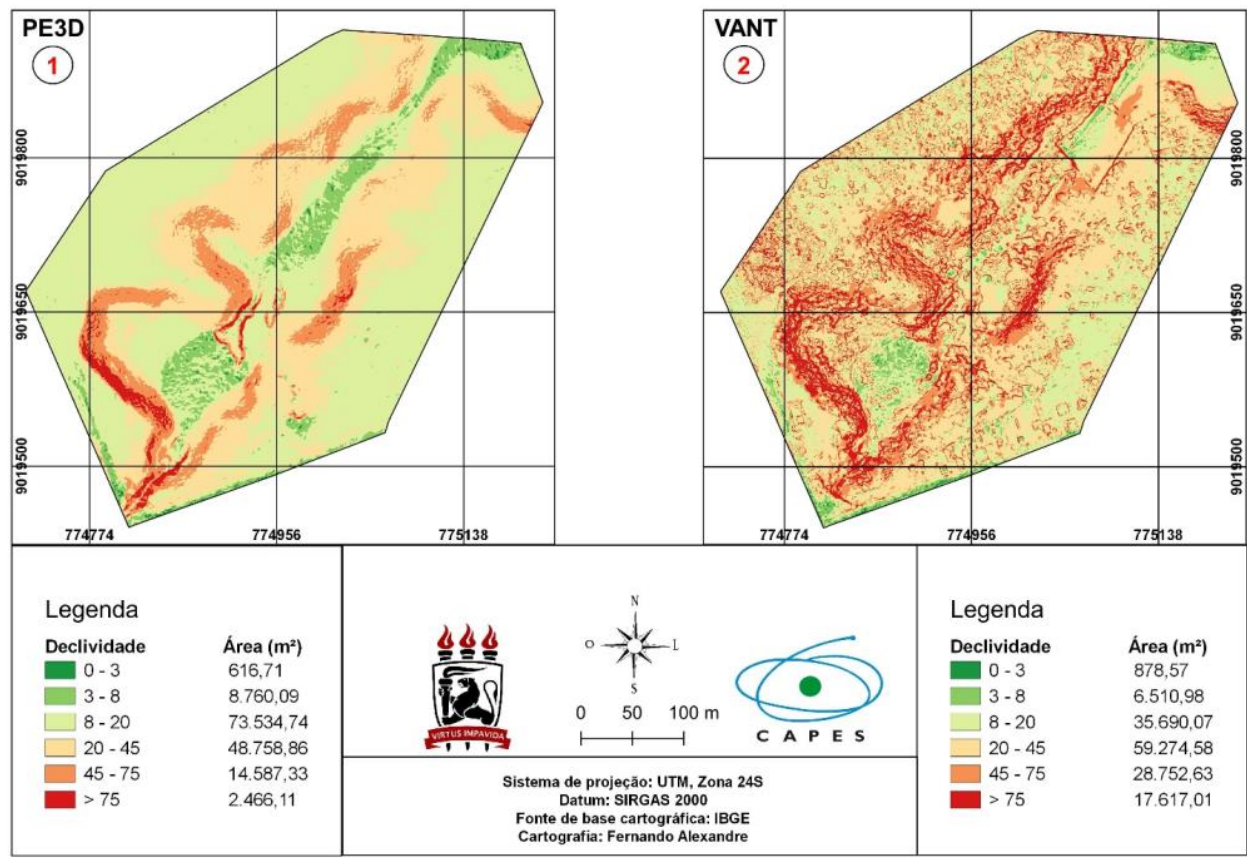

Figura 3. Declividade da voçoroca dos anos de 2016 e 2018. 
Revista Brasileira de Geografia Física v.14 n.02 (2021) 758-769

As áreas com declividades de $8-20$ 。 apresentam uma diminuição entre os anos, possivelmente houve o aumento da declividade da encosta, consequentemente sendo classificado como alta declividade a partir do MDTVAN T. Contudo, é perceptível o aumento das altas declividades, principalmente nas encostas da

voçoroca, como consequência erosivas, a partir disso já se torna possível entender quais as áreas foram mais erodidas.

Mudanças na morfologia e volume erodido

A Figura 4 apresenta os seis perfis laterais, onde se percebe a drástica diferença entre as superfícies, no perfil A - B ocorre diferenças de até
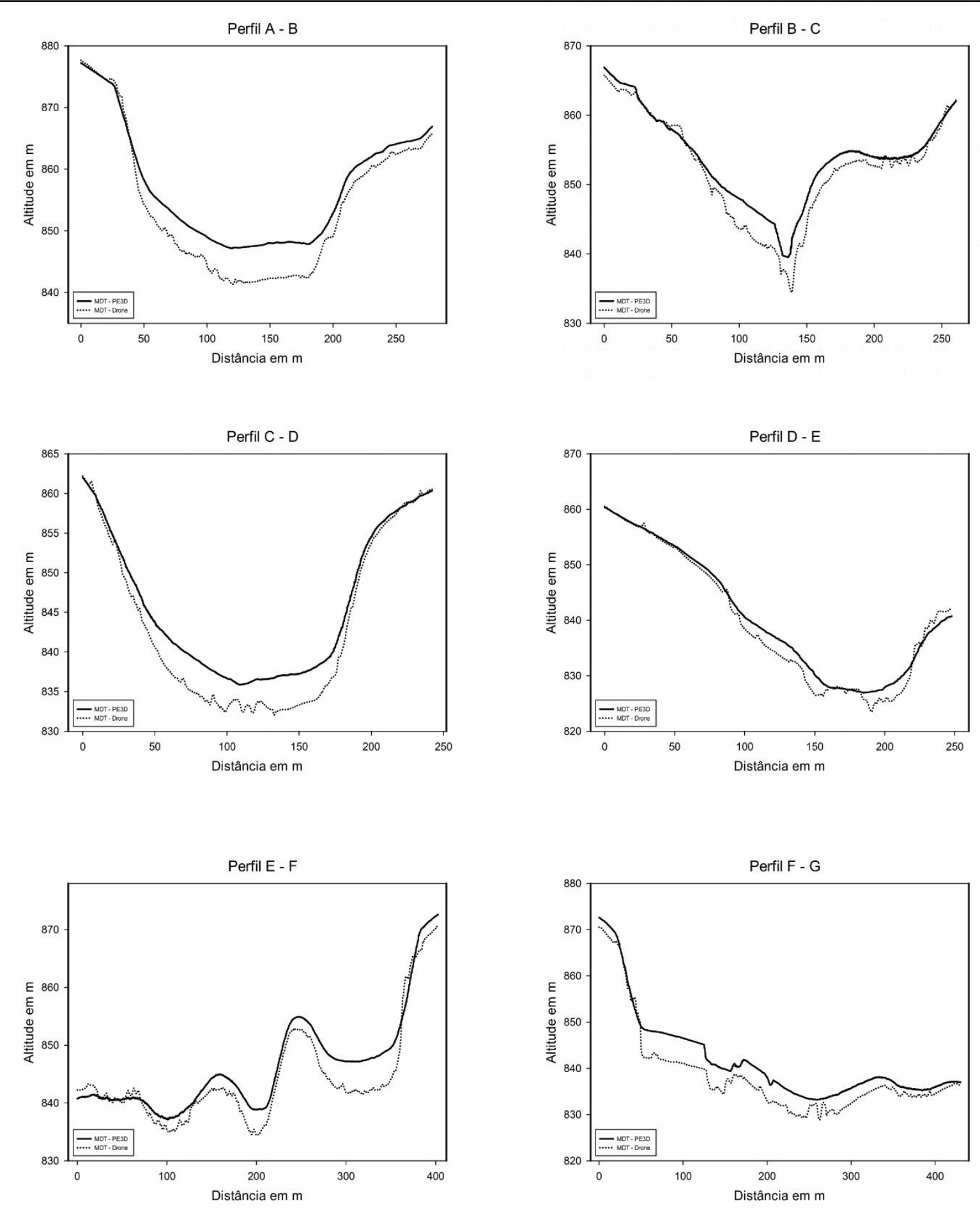

Figura 4. Perfis laterais traçados para a verificação morfológica. 
Revista Brasileira de Geografia Física v.14 n.02 (2021) 758-769

6,30 metros entre as superfícies, com alta taxa de erosão dentro da voçoroca, pode-se explicar tal motivo em decorrência de que é a área em que todo o fluxo superficial se direciona para ela, já que as encostas convexas direcionam e aumentam a velocidade do fluxo que passa inicialmente por essa área, além da ausência de vegetação arbórea.

No perfil B - C é possível ver o perfil lateral do principal sulco que concentra a água superficial dentro da voçoroca, onde toda a energia de fluxo exposto no perfil A - B posteriormente converge, porém de forma mais canalizada e com maior poder erosivo. $\mathrm{O}$ perfil $\mathrm{C}-\mathrm{D}$ apresenta uma área com média declividade, sendo com o segundo maior compartimento de captação pluviométrica e não apresenta vegetação arbórea, tendo áreas com diferenças de até 4,8 metros entre as duas datas.
O perfil D - E foi o que apresentou menor diferença entre as superfícies, deve-se levar em consideração que é uma área com baixa declividade e presença de vegetação, que diminui a velocidade do fluxo pluvial. No perfil E - F e F $\mathrm{G}$ são apresentadas as áreas já faladas, porém de forma conectada, o que permite visualizar que ao longo da extensão da voçoroca com a menor declividade e presença de vegetação há uma diminuição considerável na erosão.

O volume de material foi erodido, foi calculado a diferença volumétrica entre as duas superfícies, o que resultou no valor de 143,039,24 $\mathrm{m}^{2}$. Para se compreender como tamanha diferença de volume entre as duas superfícies se deu, foram analisados os fatores que poderiam influenciar

Tabela 1: Pluviosidade na cidade de Garanhuns entre 2016 e 2018.

\begin{tabular}{c|cccccccccccc}
\hline Ano & Jan & Fev & Mar & Abr & Mai & Jun & Jul & Ago & Set & Out & Nov & Dez \\
\hline $\mathbf{2 0 1 6}$ & 127,9 & 43,6 & 24 & 42,8 & 77,6 & 72,1 & 74,5 & 41,3 & 20,4 & 12,7 & 2 & 2,4 \\
\cline { 1 - 1 } & 11,4 & 1 & - & 51 & 340,4 & 209,1 & 342,6 & 147,2 & 127 & 17,8 & 22 & 18 \\
& 49,2 & 79,4 & 53,7 & 177,2 & 128,8 & 78,1 & 86,2 & 37,8 & 20 & 5 & 10,2 & 30,8 \\
\hline Média & 51,37 & 47,85 & 67,58 & 78,92 & 104,73 & 136,92 & 122,37 & 87,40 & 46,02 & 22,99 & 13,83 & 31,45 \\
\hline
\end{tabular}

\section{Pluviosidade média mensal}

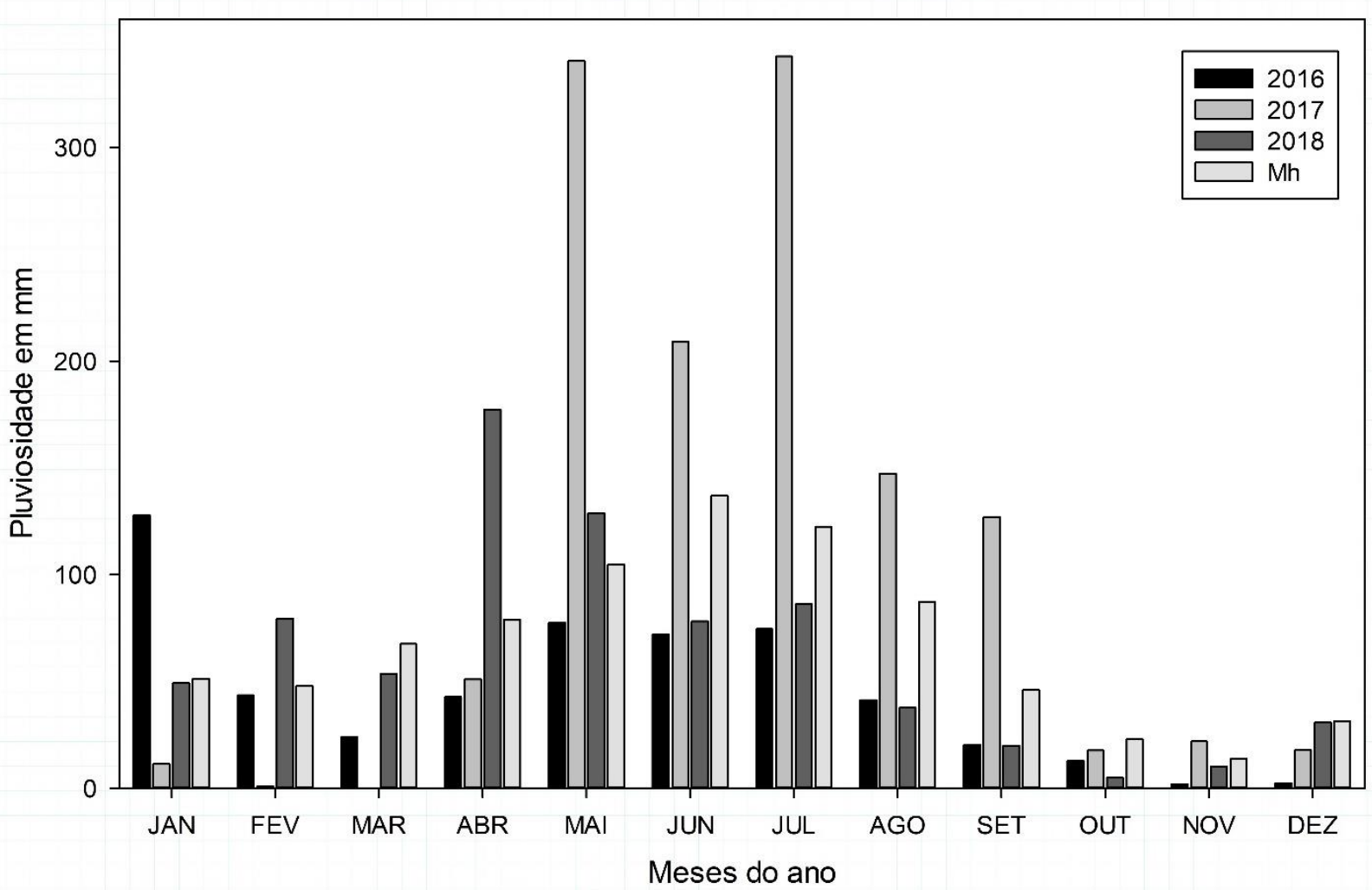

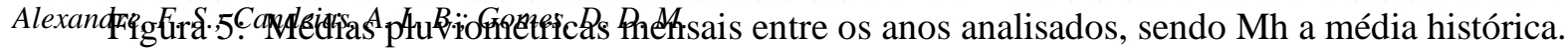


nessas taxas de erosão, como vegetação, litologia, solos, topografia e pluviosidade.

Porém a única diferença temporal entre fatores citados foi na pluviosidade, conforme a Tabela 1 e Figura 5, as médias pluviométricas de 2016 a 2018 e média histórica da estação com período regular de observação de 24 anos. Percebese a primeira anomalia nas médias no ano de 2017, que apresentam fortes chuvas, chegando em maio a $340,4 \mathrm{~mm}$ mensais, sendo $241,5 \mathrm{~mm}$ no intervalo de 5 dias seguidos $(25-29)$, com pico diário de $79,4 \mathrm{~mm}$, enquanto que a média histórica é de $104,73 \mathrm{~mm}$ mensais.

No mês de junho de 2017 há novamente fortes chuvas, acumulando um total de $209,1 \mathrm{~mm}$ mensais, mas distribuídos em todo o mês, com pico máximo diário de $16,0 \mathrm{~mm}$. No mês de julho de 2017 há novos eventos pluviométricos acima da média, totalizando $342,6 \mathrm{~mm}$ mensais, à medida que a média histórica é de 132,37 mm.

O total do mês foi precipitado em 28 dias, atingindo o pico máximo de $36 \mathrm{~mm}$ no dia 08 . As fortes precipitações destes três meses de 2017 fogem totalmente das médias mensais históricas, o que pode explicar a grande diferença volumétrica entre as duas datas.

As mudanças ocorridas na morfologia do polígono de estudo podem ser vistas na Figura 6. Percebe-se que as áreas erodias se localizam dentro da voçoroca, de forma contínua, porém as áreas mais afetadas são onde há a maior velocidade de fluxo superficial, corroborando assim as mudanças de declividade e as variações vistas nos perfis.

A voçoroca do bairro Dom Hélder Câmara tem uma idade evolutiva média de 20 anos, porém com apresenta grandes taxas erosivas, demonstrando uma forte dinâmica atuante na localidade que difere de algumas outras áreas do globo. Como comentado por Liu, Qian et al. (2019), que as voçorocas com o passar dos anos tendem a estabilidade erosiva, os autores baseiam seus argumentos com base em acompanhamento erosivos de aproximadamente 239 mil voçorocas localizadas na China.

\section{Conclusões}

As geotecnologias se mostram de grande viabilidade para estudos multitemporais e em escala de detalhe, desde que que sejam respeitadas as limitações, como a impossibilidade da remoção total da rugosidade da vegetação do MDT e a diferença entre os dados trabalhados, carecendo assim da definição de uma escala que permita a analise integrada dos dois dados.
Os perfis se mostraram de grande viabilidade para a visualização da morfologia e mudanças topográficas dentro da voçoroca, mesmo se trabalhando com dados obtidos de formas diferentes. Levando-se em consideração as distintas superfícies, a realização da quantificação somente seria exata com dados obtidos como mesmo método, porém se pode atestar a veracidade representativa dos perfis e das superfícies tendo em vista que os segmentos fora do perímetro da voçoroca não apresentam diferenças nas superfícies, somente as áreas dentro do perímetro.

A espacialização erosiva dentro da voçoroca permite a conclusão que a voçoroca se encontra ativa e transportando sedimentos, o polígono analisado apresentou diferença volumétrica de aproximadamente $71.519 \mathrm{~m}^{3}$ de sedimento. Para tanto se torna necessário maiores estudos que possam compreender a dinâmica da voçoroca e as taxas erodidas em maior período e frequência de tempo, tendo em vista que somente duas datas não permitem a compreensão de sua normalidade.

Os estudos geomorfológicos no brasil envolvendo voçorocas urbanas são recentes, e na região semiárida ainda mais escassos o que torna ainda mais necessário a realização de estudos para uma maior compreensão do fenômeno no semiárido brasileiro.

Espera-se que esse estudo possa ser usado por gestores e tomadores de decisão, visando a criação de políticas públicas com finalidade de mitigar os efeitos na área e consequentemente evitar riscos as vidas humanas que moram no entorno da voçoroca do bairro Dom Hélder Câmara. 


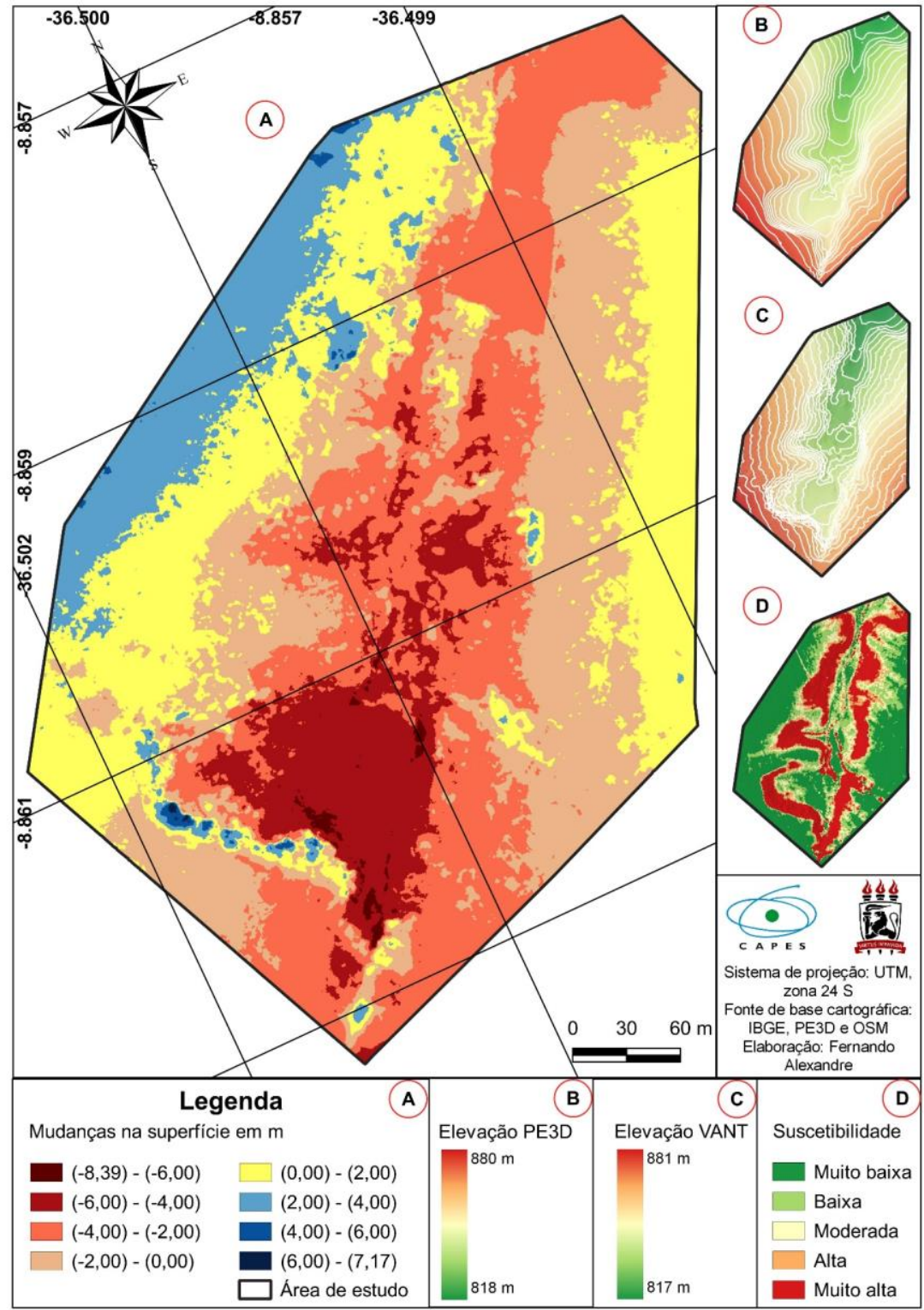

Figura 6: Áreas com acreção e erosão da voçoroca entre os anos de 2016 e 2018.

\section{Agradecimentos}

Os autores agradecem a Universidade Federal de Pernambuco (UFPE) e a Coordenação de Aperfeiçoamento e Pessoal de Nível Superior (CAPES) pela concessão de bolsa de mestrado ao primeiro autor.

\section{Referências}

Alexandre, Fernando da Silva et al., 2017. Aerofotogrametria de pequeno formato aplicada a realização da cartografia básica da cidade de Palmeirina-PE. Os Desafios da Geografia Física na Fronteira do Conhecimento, v. 1, n. 2017, p.
5565-5572.

Disponível: https://doi.org/10.20396/sbgfa.v1i2017.2220. Acesso: 12 de março de 2020.

Alexandre, Fernando da Silva; Candeias, Ana Lúcia Bezerra; Gomes, Daniel Dantas Moreira, 2020. Modelagem cartográfica para a delimitação das paisagens da bacia hidrográfica do Alto Curso do Rio Mundaú Pernambuco/Alagoas, Nordeste, Brasil. Revista Brasileira de Geografia Física (online), v. 12, n. 7, p. 2489-2502, 31 jan. Disponível: 
https://doi.org/10.26848/rbgf.v12.7.p\%25p.

Acesso: 25 de abril de 2020.

Arabameri, Alireza et al, 2019. Gully erosion susceptibility mapping using GIS-based multicriteria decision analysis techniques. Catena (online), v. 180, p. 282-297.

Arabameri, Alireza e Pourghasemi, Hamid Reza, 2019. Spatial modeling of gully erosion using linear and quadratic discriminant analyses in GIS and R. In: Spatial Modeling in GIS and R for Earth and Environmental Sciences. Elsevier, p. 299-321.

Arabameri, Alireza, Pradhan, Biswajeet; Bui, Dieu Tien, 2020. Spatial modelling of gully erosion in the Ardib River Watershed using three statistical-based techniques. Catena (online), v. 190, n. June 2019, p. 104545.

Arabameri, Alireza, Pradhan, Biswajeet e Lombardo, Luigi, 2019. Comparative assessment using boosted regression trees, binary logistic regression, frequency ratio and numerical risk factor for gully erosion susceptibility modelling. Catena, v. 183, p. 104223.

Azambuja, Renata Nunes Análise, 2007. Análise Geomorfológica em áreas de expansão urbana no município de Garanhuns - PE. Dissertação (Mestrado). Recife, Universidade Federal de Pernambuco.

Campo-Bescõs, M. A. et al, 2013. Evaluation of a gully headcut retreat model using multitemporal aerial photographs and digital elevation models. Journal of Geophysical Research: Earth Surface, v. 118, n. 4, p. 2159-2173. Disponível: https:// doi:10.1002/jgrf.20147. Acesso: 14 de maio de 2020.

Cândido, Bernardo M. et al, 2020. High-resolution monitoring of diffuse (sheet or interrill) erosion using structure-from-motion. Geoderma, v. 375. Disponível: <https://doi.org/10.1016/j.geoderma.2020.114477>. Acesso: 8 de dezembro de 2020 .

Castillo, C.; Gómez, J. A, 2016 A century of gully erosion research: Urgency, complexity and study approaches. Earth-Science Reviews, v. 160, p. 300-319. Disponível: http://dx.doi.org/10.1016/j.earscirev.2016.07.0 09. Acesso: 6 de maio de 2020.

Daba, Shibru; Rieger, Wolfgang; Strauss, Peter, 2003. Assessment of gully erosion in eastern
Ethiopia using photogrammetric techniques. Catena (online). V. 50, p. 273-291.

Domazetović, Fran et al, 2019. Development of automated multicriteria GIS analysis of gully erosion susceptibility. Applied Geography (online), v. 112. P. 102083.

Frankl, Amaury et al, 2012. Gully head retreat rates in the semi-arid highlands of Northern Ethiopia. Geomorphology (online)., v. 173-174, p. 185195. Disponível: http://dx.doi.org/10.1016/j.geomorph.2012.06. 011. Acesso: 12 de maio de 2020.

Gafurov, Artur M.; Yermolayev, Oleg P., 2020. Automatic Gully Detection: Neural Networks and Computer Vision. Remote Sensing (online)., v. 12, n. 11, p. 17-43. Acesso: 8 de maio de 2020.

Gomes, Daniel Dantas Moreira, 2015. Geoprocessamento aplicado à análise e zoneamento dos sistemas ambientais da bacia hidrográfica do Rio Mundaú - PE/AL. Tese (Doutorado). Fortaleza, Universidade Federal do Ceará.

Hosseinalizadeh, Mohsen et al, 2019. Spatial modelling of gully headcuts using UAV data and four best-first decision classifier ensembles (BFTree, Bag-BFTree, RS-BFTree, and RFBFTree). Geomorphology, v. 329, p. 184-193. Disponível:

<https://doi.org/10.1016/j.geomorph.2019.01.0 06>. Acesso: 8 de dezembro de 2020.

Infanti Jr, N.; Fornasari Filho, N., 1998. Processos de dinâmica superficial. In: Oliveira, A. M. Dos S.; Brito, S. N. A. (Org.). Geologia de Engenharia. São Paulo: Associação Brasileira de Geologia de Engenharia, P. 131-152.

Liu, Honghu et al., 2019. Using 3D scanner to study gully evolution and its hydrological analysis in the deep weathering of southern China. Catena (online), v. 183.

Liu, Honghu et al., 2020. Using high-resolution aerial images to study gully development at the regional scale in southern China. International Soil and Water Conservation Research.

Liu, J.; Liu, H., 2020. Soil erosion changes during the last 30 years and contributions of gully erosion to sediment yield in a small catchment, southern China. Geomorphology, v. 368. Disponível:

https://doi.org/10.1016/j.geomorph.2020.10735 7. Acesso: 13 de outubro de 2020. 
Marchioro, Eberval, Andrade, Edilene E. e Oliveira, João Carlos, 2016. Evolução espaçotemporal de voçorocas no espírito santo: estudo de caso nos municípios de afonso cláudio e alegre. Revista Brasileira de Geomorfologia (online)., v. 17, p. 191-204.

Martins, B. et al., 2020. The development of gullies in a Mediterranean environment: The example of the Corgo gully (central Portugal). Energy Reports (online)., v. 6, p. 794-799. Disponível: https://doi.org/10.1016/j.egyr.2019.11.004.

Acesso: 29 de maio de 2020.

Marzolff, I.; Poesen, J., 2009. The potential of 3D gully monitoring with GIS using highresolution aerial photography and a digital photogrammetry system. Geomorphology (online), v. 111, n. 1-2, p. 48-60, Disponível: https://doi.org/10.1016/j.geomorph.2008.05.04 7. Acesso: 18 de abril de 2020.

Poesen, Jean et al., 2003. Gully erosion and environmental change: Importance and research needs. Catena (online), v. 50, n. 2-4, p. 91-133. Disponível: https://doi.org/10.1016/S03418162(02)00143-1. Acesso: 4 de maio de 2020.

Real, Ligia Sampaio Corte et al., 2020. Proposition for a new classification of gully erosion using multifractal and lacunarity analysis: A complex of gullies in the Palmital stream watershed, Minas Gerais (Brazil). Catena (online), v. 186, n. April 2019, p. 1-21. Disponível: https://doi.org/10.1016/j.catena.2019.104377. Acesso: 6 de maio de 2020.

Rosa, Roberto, 2009. Introdução ao sensoriamento remoto. 7. Ed. [S.1.]: EDEFU.

Rubira, Felipe Gomes; Melo, Georgea do Vale de Melo; Oliveira, Filipe Kallás Suhadolnik, 2016. Proposta De Padronização Dos Conceitos De Erosão Em Ambientes Úmidos De Encosta. Revista de Geografia (Recife) (online), v. 33, n. 1.

Disponível:https://periodicos.ufpe.br/revistas/r evistageografia/article/view/229235/0. Acesso: 15 de janeiro de 2020.
Silva, Cristiano Alves Da et al., 2015. Utilização de VANT para geração de ortomosaicos e aplicação do Padrão de Exatidão Cartográfica (PEC). XVII Simpósio Brasileiro de Sensoriamento Remoto - SBSR, João PessoaPB, Brasil, INPE, n. 1, p. 6381-6388.

Sopchaki, Carlos Henrique et al., 2018. Verificação da qualidade de ortomosaicos produzidos a partir de imagens obtidas com aeronave remotamente pilotada sem o uso de pontos de apoio. Raega - O Espaço Geográfico em Análise (online), v. 43, n. 0, p. 200-214. Acesso: 12 de abril de 2020 .

Sousa, Alik Timóteo de, 2010. Caracterização De Voçorocas Em Bordas De Relevo Residual Tabular Em Quirinópolis-Go. Tese (Doutorado). Goiania, Universidade Federal de Goiás.

Souza, Raul Morais et al., 2019. UAV Photogrammetry: Land Survey and Soil Loss Estimation of Gully Erosion UAV Photogrammetry: Land Survey and Soil Loss Estimation of Gully Erosion in Ouro Branco, MG, Brasil. Geotechnical Engineering in the XXI Century: Lessons learned and future challenges, n. December, p. 0-8. Disponível: https://doi:10.3233/STAL190230

Vanmaercke, Matthias et al., 2016. How fast do gully headcuts retreat?. Earth-Science Reviews, v. 154 , p. 336-355. Disponível: https://doi.org/10.1016/j.earscirev.2016.01.009 . Acesso: 1 de maio de 2020.

Vrieling, A. et al., 2007. Automatic identification of erosion gullies with ASTER imagery in the Brazilian Cerrados. International Journal of Remote Sensing (online), v. 28, n. 12, p. 2723 2738, 29 jun. Disponível em: <https://www.tandfonline.com/doi/full/10.1080 /01431160600857469>. Acesso: 6 de maio de 2020. 